\title{
Analysis of Financial Risk Management Strategies of Microfinance Banks
}

\author{
0. J. Oyetayo1, S. U. Eboigbe ${ }^{2}$ \\ ${ }^{1}$ Department of Banking and Finance, Federal University of Agriculture, Abeokuta, Nigeria \\ ${ }^{2}$ Department of Banking and Finance, University of Benin, Benin City, Nigeria \\ Email: tosin_julie@yahoo.com, sharlywest.eboigbe@uniben.edu
}

How to cite this paper: Oyetayo, O. J., \& Eboigbe, S. U. (2018). Analysis of Financial Risk Management Strategies of Microfinance Banks. Journal of Financial Risk Management, 7, 223-240. https://doi.org/10.4236/jfrm.2018.73015

Received: July 3, 2018

Accepted: September 18, 2018

Published: September 21, 2018

Copyright $\odot 2018$ by authors and Scientific Research Publishing Inc. This work is licensed under the Creative Commons Attribution International License (CC BY 4.0).

http://creativecommons.org/licenses/by/4.0/

(c) (i) Open Access

\begin{abstract}
Risk taking is described as an integral part of financial services. For micro-financing in particular, engaging in proactive risk taking is essential to their viability and long term sustainability. Maintaining a good strategy that ensures an optimal mix in risk-return trade-off is much more important for the microfinance banks (MFBs) that operate on a for-profit basis. Having faulted the value-at-risk technique which is common in the asset and liability literature, we introduce the multi-stage stochastic programming using econometric time series model. Specifically, for the scenario generation, we specify a $\mathrm{VaR}$ model with the inclusion of dichotomy regime which captures the multi-stage characteristics of assets. We use the liability derived investment (LDI) model to generate the liability series over the period of study. The optimization result showed that MFBs in Nigeria are by far more risk averse than they are profit seeking. This comes with the attendant effect of not being able to achieve the outreach and sustainability objectives to the fullest. MFBs in Nigeria need to look into their investment strategy with a view to structuring the mix and value of the balance sheet components at different periods to meet their stated objectives.
\end{abstract}

\section{Keywords}

Microfinance Banks, Asset and Liability, Risk, Viability, Sustainability

\section{Introduction}

A crucial part of financial services and of micro-financing in particular is risk taking. Indeed, essential to the long-term sustainability and management of microfinance organizations (MFOs) is proactive risk taking. It is believed that for MFOs to take advantage of new opportunities and minimize threats to their fi- 
nancial sustainability, effective risk management must be carried out (Mago, Hofisi, \& Mago, 2013; Fernado, 2007; Campion \& Frankiewicz, 1999). Therefore, as they perform their role of financial intermediation in the economy, microfinance organizations consciously take risks. Like all other financial institutions, microfinance organizations (MFOs) including microfinance banks (MFBs) face risks that they must manage efficiently and effectively for their survival and sustainability (Mangold, 2016). These risks include: credit risk, interest rate risk, liquidity risk, and operational risk. Borrowers, lenders, donors and savers tend to loose confidence in the organization and funds begin to deplete when risks are poorly managed, and financial losses occur. Therefore, an MFB is not able to meet its social objective of providing financial services to the poor and quickly goes out of business when funds deplete (Ledgerwood, 1999; Dunford, 2000).

As an interventionist programme aimed at achieving the goals of financial deepening at the grassroots sector of the economy, the activities of MFOs (including MFBs) cannot be overlooked (Microfinance Newsletter, 2009). Broadly speaking, MFBs are saddled with responsibilities which can be summarized in two objectives; 1) increasing client outreach in terms of number of customers, loans and deposits 2) sustaining their organization through meager but sustainable profits, effective loan recovery, and loan screening. These two are further classified respectively as social and financial objectives. Achieving the two objectives summarized as the social and financial objectives, involves risk taking, identification, measurement and control. The rewards of good performance and costs of poor performance are rising as MFBs play an increasingly important role in local financial economies and compete for customers and resources (Joachim, 2000). For any microfinance organization (MFO) or non-bank financial institution (NBFI) it is fundamental to have a properly designed risk management framework. This refers to any operative system designed to protect an organization from the occurrence of undesired events i.e. downside risks and to enable the organization take advantage of opportunities i.e. upside potential (Mack, 2015).

Campion (2000) gave several reasons for MFBs to consider more sophisticated approaches to risk management. First, as a result of serving more customers and larger geographic areas, as well as offering a wider range of financial services and products many MFBs have grown rapidly. Second, MFBs increasingly rely on market-driven sources of funds, whether from outside investors or from local deposits and member savings to fuel their lending growth. They will have to maintain good financial performance and avoid unexpected losses in order to preserve their access to those funding sources. Third, issues of organizational structures and operating environments of MFBs can provide unique challenges to their performance. Due to their mission, they may be very decentralized or too centralized (both can be a risk), tend to be labor- and transaction-intensive, have concentration risk in certain regions or sectors (e.g., agriculture), and often operate in volatile and fragile financial markets. Finally, effective risk measurement, management and control can be achieved through cost-effective and effi- 
cient operations which is essential to achieving financial viability for MFBs.

Of all the risks faced by a MFB, financial risk has been identified as the most crucial as it relates directly with their core business which is credit administration and deposit taking. It is important that MFBs maximize their return and at the same time keep the downside risk low. The gain/return (upside potential) must increase to a point where further increases will result in a loss. This situation describes the point of optimality which the MFBs must always crave for if they are to remain in business. With regards to managing financial risk, the literature is replete with studies on financial institutions in general. Using case studies of countries with the aid of established financial and economic investor utility and portfolio optimization theories like the von Neuman-Morgensten expected utility maximization, mean-variance approach, portfolio at risk, value-at-risk and expected shortfall, researchers have conducted studies on the asset and liability management activities of financial institutions in general and the corresponding weight and direction of financial risks they carry.

The issue of asset and liability management in the money market i.e. deposit taking financial institutions in general is more dynamic. The components of the portfolio (assets and liabilities) are subjected to changes in terms of structure and amount from time to time and at different stages of transaction. Especially for MFOs (which include Microfinance Banks-MFBs), their balance sheet components are said to be even more dynamic than those of commercial banks (Greuning, Gallardo, \& Randhawa, 1998). A particular MFB may have different results (whose variations are quite significant) for its portfolio at risk, value-at-risk measurement at different periods and stages within a particular time horizon because of the dynamic nature of the components of its balance sheet. A particular combination that is found optimal at a particular period may no more be optimal after a short period. In order to remain viable, optimality must be achieved and sustained over a long time horizon.

More recently, the stochastic programming (SP) technique for measuring and managing risk for financial decisions has become very popular and very effective. Pioneer authors in stochastic programming method for bank asset and liability; Kusy \& Ziemba (1986), argue that a bank must determine its optimal trade-off between risk, return and liquidity as a necessary requirement in the asset-liability management process. SP application cuts across the different areas of businesses in the financial markets like; pension fund, mutual fund, insurance investments, banking and financing institutions in general (Bajram \& Can, 2013; Yang, 2009, Grebeck \& Rachev, 2005). However, its application to microfinance institutions is very rare in the literature.

Talking about risk evaluation for MFBs in Nigeria, some authors have attempted to analyse the nature and dimension using conventional risk evaluation techniques. In the recent past, Ndibe, Igbokwe, Dauda, \& Abdulazeez (2013) did a study on microfinance banks in Nigeria using the trend analysis. They concluded that MFBs in Nigeria are downside risk averse at the same time not harnessing the upside opportunities that abound. Their position was guided by an- 
other study carried out earlier, by Joachim (2009), which concluded that there is the absence of prudential strategies of balance sheet management of MFBs in Nigeria. But what exactly should we be concerned about in the risk management strategies of deposit money banks example of which is the microfinance banks? or what method should we adopt in assessing their risk management strategies?. Fundamental bank management theory (Greenbaum and Thakor, 1998) defines risk management as a process of risk identification, measuring, monitoring and controlling. It thus follows that any meaningful technique or method for risk evaluation must consider the aforementioned. Therefore, a research in the analysis of the asset and liability management of MFBs will have issues in setting the appropriate objectives as well as employing appropriate methodology. Essentially, it is part of this methodological gap that we intend to fill in this paper. In order to do this, we seek to provide answers to the following questions; is the risk-return trade-off in asset and liability management of MFBs optimal? To what extent do strategies adopted by MFBs favour more of down-side risk reduction or upside potential increase? The rest of this paper is divided into four sections starting from reviews, methodology, results and discussion, concluding comments.

\section{Reviews}

As established in the finance and economics literature, asset and liability management (ALM) is important for all institutions in order for them to match their assets with liabilities (Grebeck \& Rachev, 2005). Both asset and liability involves returns that must be earned on one hand, and returns that must be paid on the other hand. Earning and paying these returns however, comes with different dimensions of risk (Grebeck \& Rachev 2005; Tokat, Rachev, \& Schwartz, 2003). Therefore at the heart of ALM is the risk-return concept. Firms need to design a clear-cut framework with realistic objectives for meeting their ALM needs.

The position of the modern portfolio theory (i.e. mean-variance, VaR, Es) has been towards identification, measuring and managing the downside risk (i.e. risk of loss). According to the mean-variance approach (Markowitz, 1952, 1959), with its many variants like the standard and unstandard CAPM (Sharpe, 1964; Linter, 1965b), inter-temporal CAPM (Merton, 1973a), multifactor pricing model (Ross, 1976), etc., deviations (positive or negative) around the mean or what is called the expected value is summed up to give the variance and subsequently the standard deviation (SD). In this case, the emphasis is on the mean which is seen as the breakeven point. The calculated variance and standard deviation defines the level of risk the institution is carrying. This position is further refined in the CAPM and APT models where a linear equation is specified and a coefficient of $\beta$ (beta) is assigned to risk. The argument of the modern portfolio theory is built on the assumption of normality where the distribution of events is expected to follow a normal curve. On this curve, the standard deviation and variance considers values to the left of the mean where it is observed that the higher the SD or variance, the greater the risk of loss to the firm. 
The value-at-risk (VaR) and expected shortfall (Es) are also premised on the issue of loss. VaR defines a quantile i.e. in percentage, the maximum level of acceptable risk. This level is represented mathematically as $(1-\alpha) \star 100 \%$ percentile. Usually, the $\alpha$ quantile is given as $5 \%$ which is the maximum the firm is expected to tolerate in its business activities. This simply means that the firm must have at least $95 \%$ confidence that a particular transaction will yield gain/profit. Otherwise, it is not worth it. However, it is discovered that VaR does not offer any explanation beyond the $5 \%$ quantile which is mostly violated in actual practice. Realistically, firms often suffer losses that go beyond the $5 \%$ upward, incurring more losses than expected. This situation gave rise to the expected shortfall (Es) or the conditional $\mathrm{VaR}$ which provides analysis on the density and frequency of losses beyond the acceptable region.

Artzner, Delbaen, Eber and Heath (1999) gave four axioms that define a coherent measure of risk. This represents characteristics that all risk measures should possess in order to qualify as a coherent risk measure. They are given as 1) monotonicity 2) translation invariance 3) positive homogeneity 4) sub-additivity. By the definition of the first three characteristics, VaR being a quantile is qualified. However, VaR violates the last axiom which is sub-additivity. Hence, VaR cannot be accepted as a coherent risk measure. In case we still go ahead to specify a VaR equation for optimization, we may achieve a result that is not representative of the entire component of the portfolio assets and weights.

As for Expected shortfall (Es), Acerbi \& Tasche (2002) established that when the equation function used is a continuous density type, it may make Es to be qualified as a coherent risk measure. However a continuous density function is not common in optimization where portfolio can carry different weights and mix over time. Moreover, in the recent theoretical research in risk management, measures based on quantiles have been found to be good functions to measure the risk in a portfolio. Interestingly, the value-at-risk (VaR) still remains a reference for many financial applications, even though it is not a coherent measure in terms of the four axioms specified by Artzner et al. (1999). The attraction in VaR approach may be as a result of the fact that it is easy to interpret; monetary values can be used and financial institutions can carry out an estimation of the necessary volume of own funds to cover risk of market in business activities.

The most striking characteristic of the post-modern portfolio theory is its recognition of the positive and negative deviations from the mean (Rom \& Ferguson 1993; Cumova \& Nawrocki, 2003). Hence, contrary to modern portfolio theory where the positive and negative differences are summed up, the positive and negative differences are summed up differently. This results in the positive and negative deviations have led to the upside potential and downside risk arguments. Another important characteristic of the post modern portfolio theory is the identification of a target return (Sortino, 1996, 2006) which can be greater or lesser than the mean return depending on the investment strategy of the investor per time. One of the popular models in contemporary finance that have sprouted from the post-modern belief is the stochastic optimisation program- 
ming for ALM.

In the real sense, stochastic optimisation is a mathematical technique for optimizing processes where uncertainty prevails in the value of input and output variables. The opposite version of it is the deterministic optimization which is used when values of input variables and output variables are certain. Because financial variables exhibit a lot of variations and uncertainties, the stochastic programming method has been found more useful in finance. Some authors have attempted to build stochastic programming models with VaR and cVaR constraints. Usually, the VaR stochastic programming model will maximize return (Krokhmal, Uryasev, \& Zrazhevsky, 2002), while the cVaR stochastic programming model will minimize loss (Rockafellar \& Uryasev, 2000). The dynamic stochastic programming model (Yang, Gonzio, \& Grothey, 2009; Drijver, Klein-Haneveld, \& van der Vlerk, 2000; Grebeck \& Rachev, 2005; Defourny, Ernst, \& Wehenkel, 2008) incorporates both return maximization and loss minimization which provides better answers to the asset and liability issues of banks.

An important line of difference observed in $\mathrm{VaR}, \mathrm{cVaR}, \mathrm{PMPT}$ and stochastic programming optimization models comes in the stating of risk and return constraints. In $\mathrm{VaR}$ and $\mathrm{cVaR}$ optimization model, the return constraint is assumed to be constant while the risk constraint is allowed to be dynamic. Whereas the dynamic stochastic optimization model premised on the post-modern idea of simultaneous risk minimisation and return maximisation and the specification of a target return, allows both return and risk constraints to be dynamic.

\section{Methodology}

1) The Multi Stage dynamic stochastic programming framework

Stochastic programming is characterized by the construction of event trees which specifies different scenarios for the occurrence of stated random variables. The event trees show the results achieved and decisions taken as information are revealed overtime. An optimal solution is determined at each stage of the event tree which will become an input in the next stage until the terminal period. The stochastic programming model formulated is usually done to fit the condition of the financial institution in question and the state of the economy at each stage.

\section{2) Construction of Event Trees for the Model}

The time horizon specified for this study is twenty five years (1992-2016). Within this period, three important stages are identified. Stages are represented with $t_{0}, t_{1}, t_{2}$ respectively from the first to the third stage. The period of the stages are; 1992-2002, 2002-2010, 2010-2016. These stages are traced from the emergence of microfinance banks in Nigeria as contained in the microfinance policy, regulatory and supervisory framework for Nigeria (CBN, 2011).

\section{Liability Generating Scenario}

In any ALM model, it is important to project the future value of the liabilities. This can be achieved using discounting methods applicable to the type of liabilities considered in the model. 


\section{Scenario for Economic factors and Asset returns}

There is a consensus in the stochastic programming for ALM literature that similar factors affect both assets and liabilities especially in the fixed income securities institutions. This position is based on the fact that ALM applications thrive on simulation systems that require the integration of asset prices with economic factors. This integration is crucial as the assets and liabilities are often affected by the same underlying economic factors. We agree with the position of (Zenios, 1995) that short term interest rate drives the returns on both assets and liabilities in fixed income ALM applications for money management. Therefore, a suitable variant of the short term interest rate; monetary policy rate (MPR) is selected for analysis in this study. Once the model for generating scenarios has been specified, the coefficients have to be calibrated in order to produce plausible values for the returns. Specifically, three methods for generating asset return scenario with more detail have been identified in literature. They are; 1) bootstrapping historical data, 2) statistical modelling with the Value-at-Risk approach, and 3) modeling economic factors and asset returns with vector autoregressive models. This study makes use of the third method which is modeling economic factors and asset returns with vector autoregressive models. Modeling economic factors and asset returns with vector autoregressive models has become more popular in the stochastic programming literature (Hoyland \& Wallace, 2001; Kouwenberg \& Zenois, 2001; Koskosides \& Duarte, 1997). It is less complex in terms of computation and the limitations on the time series model are not as serious as that of value-at-risk and historical bootstrapping.

From the foregoing, we specify a stochastic model that maximizes expected return for MFBs investment over the specified time horizon. The stochastic linear programming (SLP) used in this study has been applied successfully to a number of related problems. Few examples of such are applications in insurance (Cariño \& Ziemba, 1998; Cariño et al., 1994), pension fund industry (Drijver, 2005; Gondzio \& Kouwenberg, 2001). Zenios (1999) also used survey large-scale applications of SLP to fixed income portfolio management. The stochastic programming models of Yang et al. (2009), Yang (2009) on; practical application of stochastic modeling framework for investment strategy in asset and liability management are adapted with little modifications for this study.

With the objective of maximizing expected return on asset with acceptable risk, then the multi-stage ALM problem concerning the investment strategy of the MFBs can be modelled as:

$$
\begin{gathered}
\max \sum_{j T \in N T} \xi_{j T}^{T}\left(\sum_{i \in I}(1-\eta) W i x h_{i, j T}^{T}+c_{j T}^{T}-\psi b_{j T}^{T}\right) \\
\text { s.t. }(1+\eta) \sum_{i \in I} W_{i x h_{i, 0}^{0}}^{0}+c_{0}=G-A_{0}+D_{0} \\
(1+\eta) \sum_{i \in I} W_{x i x b_{i, j t}^{t}+c_{j t}^{t}}=(1-\eta) \sum_{i \in I} W_{i x s_{i, j t}^{t}}^{t}+\left(1+r_{c, j t}^{t}\right) c_{a(t, j t)}^{t-1}-A_{j t}^{t}+D_{j t}^{t}, j_{t}=1, \cdots, n_{t}, t=1, \cdots, T, \\
\left(1+R_{i, j t}^{t}\right) x h_{i, a(t, j t)}^{t-1}+x b_{i, j t}^{t}-x s_{i, j t}^{t}=x h_{i, j t}^{t}, i \in I, \quad j_{t}=1, \cdots, n_{t}, t=1, \cdots, T
\end{gathered}
$$




$$
\begin{gathered}
\sum_{i \in I}(1-\eta) W_{i} x h_{i, j T}^{T}+c_{j T}^{T}+b_{j T}^{T} \geq \theta A_{j T}^{T}, j_{t}=1, \cdots, n_{t}, t=1, \cdots, T \\
\phi\left(x h_{i, j t}^{t}, c_{j t}^{t}\right) \leq \sigma, j_{t}=1, \cdots, n_{t}, t=1, \cdots, T \\
x h_{i, j t}^{t} \geq 0, \quad x s_{i, j t}^{t} \geq 0, \quad b_{j T}^{T} \geq 0, \quad x h_{i, j t}^{t}, x s_{i, j t}^{t}, x b_{i, j t}^{t} \in \mathbb{R}^{m} \\
i \in I=\{1, \cdots, m\}, \quad j_{t} \in N_{t}=\left\{1, \cdots, n_{t}\right\}, t=1, \cdots, T,
\end{gathered}
$$

Where $\phi(\cdot)$ gives the risk associated with position $(x h, c)$.

\section{3) Definition of Variables in equations of the Multistage Framework}

Each of the equations above represents sub-objectives to be satisfied in order to achieve the overall objective of optimality in the risk-return trade-off in MFBs balance sheet. The objective function in Equation (1) aims to maximize the summation of total assets plus cash available to MFBs at each node and stage of the entire Time horizon represented by $j_{T} \in N_{T}$, multiplied by their joint probabilities $\xi_{j T}^{T}$, taking into account the penalties of underfunding and transaction fee $\eta$ deducted.

Equation (2) is the constraint equation to the maximization equation in (1), where the asset side is shown to be equal to the liabilities side in line with standard accounting/balance sheet equation. The initial assets of the MFBs represented by $W_{i} x h_{i, 0}^{0}+C_{0}$ plus transaction fee earned on these assets is equated to the initial capital less initial expenses (outflow of resources) plus the initial inflow of resources in the form of grants and donations.

Equation (3) describes the processes and activities on both the assets and liabilities sides from one period to the other that links the constraint equation to the objective function. On the liabilities side, the initial capital $G$ is expanded to become $(1-\eta) \sum_{i \in I} W_{i} x b_{i, j, j t}^{t}+\left(1+r_{c, j t}^{t}\right) C_{a(t, j t)}^{t-1}$ meaning the summation of the market value of units of liabilities raised in fresh capital from owners at each node and stage less the transaction cost incurred on them, plus cash from previous node and stage each subjected to a compounded interest rate, less $A_{j t}^{t}$ which is the outflow of resources; payment of deposits in each node and stage, plus additional inflow of resources $D_{j, t}^{t}$ in the form of grants and donations in each node and stage. On the assets side, initial asset and available cash is expanded to become market value of the units of assets disbursed as loan in each node and stage plus the transaction fee gained from them.

Equation (4) captures the inventories of total asset (earning and non-earning) at each node and stage. That is, the value of total assets in the previous node and stage plus the return on the total assets, plus value of assets raised from fresh liabilities in each node and stage, less value of assets disbursed as loan in each node and stage must be equal to the current value of total assets in each node and stage.

Equation (5) defines the underfunding level $b_{j}$ at the end of the financial period, whereby, the summation of the value of total assets for each node and stage, available cash in each node and stage, and the amount of underfunding that may exist at each node and stage less the transaction cost, is expected to be greater than or at least equal to the coefficient of funding (ratio of assets to li- 
abilities) at the end of the financial period. This equation specifies the return constraint that the MFBs face.

Equation (6) expresses the risk measure function $\phi(\cdot)$ and the maximum acceptable level of risk represented as $\sigma$ (risk constraint). According to this equation, the estimated risk quantile associated with the value of the total assets and cash available at the end of the financial period should be less or equal to the benchmark given by $\sigma$.

The last equation expresses the non-negativity constraints of the decision variables used in the model, where all variables are subsets of real financial figures.

\section{4) The vector autoregressive (VAR) model}

In order to generate the scenario for estimating asset returns with economic factors, a VAR model is specified. Following the work of Boender (1997), a baseline autoregressive model for ALM problem is given thus;

$$
\begin{gathered}
R_{t}=c+V h_{t-1}+\varepsilon_{t}, \varepsilon_{t} \sim N(0, Q), t=1,2,3, \cdots, T \\
R_{i t}=\operatorname{In}\left(1+r_{i t}\right), i=1,2, \cdots, m, t=1,2,3, \cdots, T
\end{gathered}
$$

where $m$ is the number of asset time series, $r_{i t}$ is the discrete rate of change of variable $i$ in year $t, R_{t}$ is an $\mathrm{m}$-dimensional vector of continuously compounded rates, $c$ is the m-dimensional vector of coefficients, $V$ is an $m \times m$ matrix of coefficients, $\varepsilon_{t}$ is the m-dimensional vector of error terms and $Q$ is the $m \times m$ covariance matrix.

From the return constraint in Equation (5), the following VAR is specified specifically for estimating the multi-stage dynamic returns

$$
R_{t}=a_{1}+\sum_{j=1}^{k} b_{1 j} R_{t-j}+\sum_{j=1}^{k} c_{1 j} C_{t-j}+\sum_{j=1}^{k} d_{1 j} U F_{t-j}+\sum_{j=1}^{k} e_{1 j} M P R_{t-j}+u_{1 t}
$$

where;

$$
\begin{aligned}
& R_{t}=\text { Return on asset } \\
& C_{t}=\text { Cash } \\
& U F_{t}=\text { Underfunding } \\
& M P R_{t}=\text { Monetary Policy Rate }
\end{aligned}
$$

In order to capture the multi stage characteristics of the model for the different transaction stages identified, (i.e. $t_{0}-t_{2}$ ), we introduce a dichotomy regime into the VAR model specified above. Hence the model is further specified as;

$$
\begin{aligned}
R_{t}= & a_{1}+\sum_{j=1}^{k} b_{1 j} R_{t-j}+\sum_{j=1}^{k} c_{1 j} C_{t-j}+\sum_{j=1}^{k} d_{1 j} U F_{t-j} \\
& +\sum_{j=1}^{k} e_{1 j} M P R_{t-j}+\beta_{i} \sum_{i=1}^{3} d_{i}+u_{1 t}
\end{aligned}
$$

where;

$$
\begin{gathered}
d_{i} \Rightarrow d_{1}, d_{2}, d_{3} \\
d_{1}=t_{0} \\
d_{2}=t_{1} \\
d_{3}=t_{2}
\end{gathered}
$$




\section{5) Empirical Model for Risk-Return Benchmark for Multi-stage}

In order to derive $\sigma$ which is the maximum level of risk to be used in the risk constraints, the single index, multi-period standard capital asset pricing model (CAPM) is employed in this study. According to the original model developed by Sharpe (1964) and Lintner (1965), the model for estimating portfolio return and risk are given as follows;

$$
\left(R_{p}\right)_{t}=\alpha_{p}+\beta_{p}\left(R_{m}-R_{f}\right)_{t}+\varepsilon_{i t}
$$

where; $R_{p}=$ portfolio return (return on asset), $\alpha_{p}=$ component of portfolio return independent of market return, $R_{m}=$ market index return; taken as the All Share Index (ASI) of the stock market. $R_{f}=$ Risk free rate taken as treasury bill rate, $\beta_{p}=$ expected change in $R_{p}$ given a change in $R_{m}, t=$ the period dimension $(1 \cdots N)$ where $N=25$. where $\beta_{p}=\sum_{i=1}^{n} \omega_{i} \beta_{i}$. Portfolio risk equation is given thus;

$$
\begin{gathered}
\sigma_{p}^{2}=\beta_{p}^{2} \sigma_{m}^{2}+\sum_{i=1}^{n} \omega_{i}^{2} \sigma e_{i}^{2} \\
\sigma_{p}=\sqrt{\beta_{p}^{2} \sigma_{m}^{2}+\sum_{i=1}^{n} \omega_{i}^{2} \sigma e_{i}^{2}}
\end{gathered}
$$

In order to derive the desired target return benchmark, this study adapts with adjustments, the formula of Hoevenaars et al. (2008). The formula is actually a version of the liability derived index (LDI). The LDI represents the return which brings asset and liability returns at par. Different versions of LDI for different areas of financial services have been developed over time. The choice of the Hoevanaars et al. (2008) LDI over the Sortino LDI formula is based on the fact that the latter was built for the liability of the insurance and pension industry whose liability structure is very dynamic. Since the liability structure of the MFBs is also dynamic, the model becomes most suitable to calculate the liability derived index for the MFBs.

Hence, the liability return series based on a log-linear transformation process is given by the following equation;

$$
r_{L, t+1}=\frac{1}{12} r r_{t+1}-D_{L}\left(r r_{t+1}-r r_{t}\right)
$$

where, $r r_{t}$ is the 25-Year Treasury Yield adjusted to constant maturity and $D_{L}$ is the duration of MFBs liabilities. As applied in Hoevenaars et al. (2008), the duration of MFBs liabilities is assumed to be 25 years. The model assumes that MFBs liabilities are in a stationary state and it pays full indexation. A sufficient condition for this to be true is that there are no underfunding and that assets matches liability through time.

The liability derived return calculated from the above is taken as the benchmark return to be compared with the maximized return on asset estimated from the multi-stage stochastic model.

\section{6) Data Collection}

Data for microfinance banks' current and fixed assets, revenue, operating expenses, fixed deposits, long term and subsidized loans and other long term li- 
abilities, the monetary policy rates of the banking system, all share index of the capital market were all collected from the Central Bank of Nigeria statistical bulletin 2016. Quaterly data were collected to cover for the period of years specified for each of the three stages identified for MFBs investment period.

For the asset model, return on asset was calculated as operating income /total asset per period, cash was the cash in vault and other banks, underfunding was the difference of the current asset and current liabilities per period. Data on return on asset, market return, risk free rate (treasury bill rate) was used to generate a 25 year series for risk benchmark based on the CAPM model. A 25 year series was also generated for the liability derived index model.

\section{Results and Discussion}

1) Multi-stage Stochastic Optimization for MFBs' ALM

Recall the stochastic Model;

$$
\begin{gathered}
\max \sum_{j T \in N T}\left(\sum_{i \in I}(1-\eta) W i x h_{i, j T}^{T}+c_{j T}^{T}-\psi b_{j T}^{T}\right) \\
\text { s.t. }(1+\eta) \sum_{i \in I} W i x h_{i, 0}^{0}+c_{0}=G-A_{0}+D_{0}
\end{gathered}
$$

The return constraint from which the VAR model was derived;

$$
\sum_{i \in I}(1-\eta) W_{i} x h_{i, j T}^{T}+c_{j T}^{T}+b_{j T}^{T} \geq \theta A_{j T}^{T}
$$

And the associated risk constraint for the estimated return;

$$
\phi\left(x h_{i, j t}^{t}, c_{j t}^{t}\right) \leq \sigma
$$

\section{2) Vector auto-regression Result for Multi stage variables}

The result (Table $1 \&$ Table 2 ) shows the multi stage asset-liability management of MFBs, with coefficients for return on asset, available cash, underfunding (liabilities unsatisfied) and the economic factor at the different stages. All the variables interacted significantly with the return on asset at the different stages except MRR. MRR has a negative and insignificant interaction with return on

Table 1. Descriptive statistics and normality test of multi-stage variables.

\begin{tabular}{cccc}
\hline Test/Variables & Rxh (ROA) & Cash & Under Funding \\
\hline Mean & 0.125115 & 2105.830 & -28.42381 \\
Median & 0.219361 & 1566.694 & 0.000000 \\
Maximum & 0.970279 & 12772.56 & 30.62500 \\
Minimum & -1.607081 & 2.350000 & -214.3969 \\
Std.Dev. & 0.486377 & 2589.550 & 64.10142 \\
Skewness & -1.626712 & 2.700795 & -1.992491 \\
Kurtosis & 6.401570 & 10.87193 & 5.409156 \\
Jarque-Bera & $77.54408^{*}$ & $319.0055^{*}$ & $75.89440^{*}$ \\
Observations & 100 & 100 & 100 \\
\hline
\end{tabular}

${ }^{\star} \mathbb{*}^{* *}$ denotes significance at $1 \%$ \& 5\% levels respectively. Source: Author's E-view result 2017. 
Table 2. Dependent variable Rxh(ROA), Cash, Ufund and MRR.

\begin{tabular}{|c|c|c|c|}
\hline Stages/Variables & $\begin{array}{c}\text { D1 } \\
\text { Rxh (ROA) }\end{array}$ & $\begin{array}{c}\mathrm{D} 2 \\
\mathrm{Rxh}(\mathrm{ROA})\end{array}$ & $\begin{array}{c}\text { D3 } \\
\text { Rxh (ROA) }\end{array}$ \\
\hline $\begin{array}{c}\operatorname{Rxh}(-1) \\
\text { t-statistic/prob }\end{array}$ & $\begin{array}{l}1.192802 \\
(11.6941)\end{array}$ & $\begin{array}{l}1.181909 \\
(11.3730)\end{array}$ & $\begin{array}{l}1.180452 \\
(11.2860)\end{array}$ \\
\hline $\begin{array}{c}\operatorname{Rxh}(-2) \\
\text { t-statistic/prob }\end{array}$ & $\begin{array}{l}-0.498869 \\
(-4.80181)\end{array}$ & $\begin{array}{l}-0.508717 \\
(-4.90596)\end{array}$ & $\begin{array}{l}-0.505046 \\
(-4.86550)\end{array}$ \\
\hline $\begin{array}{l}\text { UFUND (-1) } \\
\text { t-statistic/prob }\end{array}$ & $\begin{array}{c}0.000375 \\
(0.27367)^{\star *}\end{array}$ & $\begin{array}{c}0.000475 \\
(0.34679)^{*}\end{array}$ & $\begin{array}{c}0.000496 \\
(0.36222)^{\star}\end{array}$ \\
\hline $\begin{array}{l}\text { UFUND }(-2) \\
\text { t-statistic/prob }\end{array}$ & $\begin{array}{c}7.28 \mathrm{E}-05 \\
(0.05422)^{\star \star}\end{array}$ & $\begin{array}{l}-0.000235 \\
(-0.17055)^{\star}\end{array}$ & $\begin{array}{l}-0.000266 \\
(-0.19428)\end{array}$ \\
\hline $\begin{array}{l}\text { LogCash }(-1) \\
\text { t-statistic/prob }\end{array}$ & $\begin{array}{c}0.044377 \\
(1.02737)^{* *}\end{array}$ & $\begin{array}{c}0.051160 \\
(1.16521)^{\star *}\end{array}$ & $\begin{array}{c}0.051993 \\
(1.18858)^{\star *}\end{array}$ \\
\hline $\begin{array}{c}\text { LogCash }(-2) \\
\text { t-statistic/prob }\end{array}$ & $\begin{array}{c}-0.062252 \\
(-1.55781)^{\star *}\end{array}$ & $\begin{array}{c}-0.060663 \\
(-1.62149)^{* *}\end{array}$ & $\begin{array}{c}-0.065590 \\
(-1.74167)^{\star *}\end{array}$ \\
\hline $\begin{array}{c}\text { MRR (-1) } \\
\text { t-statistic/prob }\end{array}$ & $\begin{array}{l}-0.465590 \\
(-0.18775)\end{array}$ & $\begin{array}{l}-0.742531 \\
(-0.34552)\end{array}$ & $\begin{array}{l}-0.265686 \\
(-0.12412)\end{array}$ \\
\hline $\begin{array}{c}\text { MRR (-2) } \\
\text { t-statistic/prob }\end{array}$ & $\begin{array}{l}1.203834 \\
(0.48602)\end{array}$ & $\begin{array}{l}1.562558 \\
(0.86103)\end{array}$ & $\begin{array}{l}1.705136 \\
(0.78311)\end{array}$ \\
\hline $\mathrm{D}(-1)$ & $\begin{array}{l}-0.055736 \\
(-0.19573)\end{array}$ & $\begin{array}{l}0.023343 \\
(0.12551)\end{array}$ & $\begin{array}{l}-0.039853 \\
(-0.15904)\end{array}$ \\
\hline $\mathrm{D}(-2)$ & $\begin{array}{l}0.041824 \\
(0.15855)\end{array}$ & $\begin{array}{l}-0.081528 \\
(-0.45215)\end{array}$ & $\begin{array}{c}0.117433 \\
(-0.15904)\end{array}$ \\
\hline $\mathrm{C}$ & $\begin{array}{l}0.072092 \\
(0.24384)\end{array}$ & $\begin{array}{l}-0.025193 \\
(-0.08612)\end{array}$ & $\begin{array}{l}-0.087139 \\
(-0.27549)\end{array}$ \\
\hline R-squared & 0.688398 & 0.922416 & 0.955520 \\
\hline Adj R-squared & 0.646851 & 0.912071 & 0.949589 \\
\hline Sum sq. residuals & 0.608711 & 1.645504 & 0.930981 \\
\hline Akaike A/C & -1.857067 & -0.862609 & -1.432173 \\
\hline Schwarz SC & -1.543139 & -0.548681 & -1.118244 \\
\hline
\end{tabular}

Source: Author's E-view result 2017.

asset. This confirms that for most of the investment period of MFBs under study, their asset and liability management has not been driven by economic factors. This is possible because for a better part of the period under study (i.e. 1992-2004), MFBs operated like charitable organizations with very little emphasis on returns. They got cheap funds from government sources and gave out loans at sub-prime lending rates. The period 2005-2010 saw MFBs operating as an appendage of the commercial banks, cheap funds from government sources were channelled to the banks at sub-prime rates. Their focus then was to minimize the downside risk as much as possible. It is not until recently after the recapitalization of MFBs (i.e. 2011-date) by which they were admitted into the mainstream financial system, that they started receiving funds and giving out loans at rates premised on the prime lending rates. That accounts for the insig- 
nificant interaction of MRR with return on asset.

For all the stages analyzed, none showed a significant effect on the interaction of the variables over the period of study. This may be explained by the fact that MFBs in Nigeria have not really improved on their investment strategy over time. Just the same way their investment strategy was at the beginning, so it is at the end of the investment horizon considered in this study. The implication is that economic and regulatory issues surrounding the existence of MFBs did not affect their asset mix and rebalancing at the different stages.

\section{3) Estimation of Return from the Maximization model}

Using the coefficients that have been generated in the VAR system, we go ahead to generate return values for each of the asset and liability management stage. The Imputing of the coefficients is done by the adjusted sampling method. For each stage; $t_{0}-t_{2}$, the average value of the corresponding variables ( $R x h$, Cash, Unfund, LDI, Risk, Transaction cost), is taken and a new value is derived to represent the entire stage. It is this average value that the corresponding coefficients are assigned to. With the aid of the Markov solver for stochastic programming, the probability and transaction cost values for asset, cash and underfunding are generated in each scenarios of the multi-stage (see appendix). Hence the stochastic model is solved for each stage of the investment horizon. The result is presented below (Table 3 ).

The optimal result above shows the calculated and benchmark estimates for both the risk and return of MFBs. Result confirms the position of the modern portfolio theory that investors are more sensitive to losses than to gains. Again, it is established in the post-modern portfolio theory that where the investor adopts a strategy of gain seeking and risk averse at the same time, the magnitude of risk averse is always higher than the magnitude of gain seeking (Cumova and Nawrocki 2003). We see from the result that the difference between the calculated downside risk and the benchmark risk is by far higher downward, than the difference between the calculated return and benchmark return upward.

Just like the submissions of earlier studies on the investment strategies of MFBs; (Joachim, 2009; Ndibe et al., 2013), our result shows that truly, MFBs are more downside risk averse than they are gain seeking. The calculated risk which is expected to be at least equal to or less than the benchmark risk is actually

Table 3. Optimal result for ALM Strategies of MFBs over the investment period.

\begin{tabular}{ccccccc}
\hline Stages & Variables & $\begin{array}{c}\text { Return } \\
\text { (Benchmark) }\end{array}$ & $\begin{array}{c}\text { Return } \\
\text { (Calculated) }\end{array}$ & $\begin{array}{c}\text { Downside } \\
\text { Risk } \\
\text { (Benchmark) }\end{array}$ & $\begin{array}{c}\text { Downside } \\
\text { Risk } \\
\text { (Calculated) }\end{array}$ & $\begin{array}{c}\text { Upside } \\
\text { Potential } \\
\text { (Calculated) }\end{array}$ \\
\hline ALM I & Rxh, Cash, Uf & $0.58736 \%$ & $0.2926 \%$ & $5.1581 \%$ & $-1.4081 \%$ & $-0.29476 \%$ \\
ALM II & Rxh, Cash, Uf & $0.175325 \%$ & $0.0365 \%$ & $9.115 \%$ & $-1.652 \%$ & $-0.138825 \%$ \\
ALM III & Rxh, Cash, Uf & $0.11176 \%$ & $0.00583 \%$ & $3.565 \%$ & $-14.4536 \%$ & $-0.10593 \%$ \\
\hline
\end{tabular}

Source: Author's calculation 2017. 
$6.5662 \%$ lower in $t_{0}, 10.74 \%$ in $t_{1}$ and $18.0186 \%$ in $t_{2}$. Whereas, the calculated return which is expected to be at least equal to or greater than the benchmark return is actually lesser by $0.29476 \%$ in $t_{0}, 0.138825 \%$ in $t_{1}$ and $0.10593 \%$ in $t_{2}$.

From the theoretical review, it is established that the issue of sustainability is tied to the level of return made by the financial institution. Return itself is tied to the issue of risk. In order to ascertain the financial sustainability of the MFBs, we consider the issue of optimality in their risk-return trade-off. Our result shows that MFBs are more sensitive to losses than to returns as established in theory. The calculated returns fall far below the benchmark optimal returns. Whereas, the calculated risk was far lower than the benchmark risk. Going by the aforementioned, we can safely say that the risk-return trade-off of MFBs in Nigeria is not optimal. MFBs favour more of downside risk reduction than upside potential increase.

\section{Discussion of Findings}

We can deduce from our result that neither the MFBs managers, investors, customers nor the government are enjoying the operations of MFBs in Nigeria yet. The goal of outreach is unmet when MFBs are not taking opportunities to reach out to more customers by offering their loans and insurance services to them (Fernado, 2007). Investors are not getting enough return as they should get from their investment in MFBs. Government is not achieving its financial deepening goal which is at the "heart" of financial development. In the same vein, customers i.e. microentrepreneurs, microentreprises and households are not getting the necessary support for business development. Generally, the goal of economic development through microfinance is not met (Komolafe 2010). Donor agencies (local and foreign) are disappointed and as such, donor funds have seriously depleted (Dunford, 2000). The evidence from Nigeria supports the notion that credit based microfinance has the characteristics of a "development fad" (Ellerman, 2007). Their lending pattern is abnormally skewed towards easy-entry micro-businesses with little potential and household consumption. Even though these are highly publicized, they have very little developmental results. Whereas microfinance investment managers provide adequate risk management and portfolio diversification for high returns in some climes (Mangold, 2016), the same is not so in Nigeria. Rather than lend to micro-businesses as expected, and directed by $\mathrm{CBN}, \mathrm{MFB}$ operators were investing the money in real estate, petroleum business, schools, stock markets and to fund LPOs (Komolafe, 2010). These investments however became trapped following the impact of the global financial crisis on the economy. In addition, following the global debate on responsible pricing in microfinance, loan pricing surveys reveals interest rate charged by Nigerian MFBs are comparatively high (SEDIN, 2015). Arising from the above, we therefore ask: 1) What makes microfinance investment in Nigeria peculiar? 2) Can the microfinance lending pattern determine their long-term sustainability? 3) Can MFBs resolve the risk-return debacle through appropriate 
loan pricing technology?

\section{Conclusion}

In achieving the objective of evaluating the overall value risk inherent in MFBs balance sheet, this study introduces the stochastic programming model. As simplistic and practical as the model has been presented in this work, some major limitations in its usage which may have influenced our result have been identified. The estimation of risk under each of the stages separated by the dichotomy variable was derived manually from the series generated for each stage. The Markov stochastic programming solver employed only generated the associated transaction cost and probability values for the imputed variables at the different stages and scenarios. A more efficient solver like the Object Oriented Programming Solver (OOPS) would have required the stochastic programming language and based on this, would supply optimal solutions for return and risk at each stage. We were limited by inability to obtain the above named solver as it was not within our reach during the period of study. However, we rely on the authenticy provided by past research works that have used econometric time series models for calibrating optimal coefficients for multi-stage returns to be used in the stochastic model.

It is very rare at least in Nigeria, to find a financial institution that operates at the optimal level of risk-return trade-off. At best, financial institutions celebrate levels a little below or close to optimality. However, in the case of the MFBs that have been studied in this work, their divergence from the optimality level is quite worrisome. It is obvious that majority of the MFBs are still far from achieving the two all important objectives of 1) outreach and 2) financial sustainability. The shortcomings of the MFBs may be premised on either of these two 1) that the existing policy framework for the operation of MFBs is not feasible considering the nature of the market they operate in, 2) that the practitioners and operators in the Microfinance Banking sector have not acquired the right skill and expertise required for their kind of business.

We conclude from our result that risk-return trade-off in the ALM of MFBs is not optimal. MFBs must first set out to identify their own distinct market. Interestingly, with the current stage of development in which Nigeria is, MFBs have larger markets than any other financial institution. Recall that the MFBs were established to serve the small and micro businesses at the grassroots level of the economy. The grassroots, rural, semi-urban areas in all the states of Nigeria are a beehive of economic activities. Although the turnover may not be as large as that of established commercial and corporate sectors, it is a very steady one. MFBs with a capital base of 20 million naira should not attempt to compete with a commercial bank with a capital base of a minimum of 25 billion naira. Similarly, operators who believe in high class luxurious service and overheads should look elsewhere other than MFBs. MFB is basically for the low income individuals and microenterprises in the rural, semi-urban areas. Operators who are serious about 
wooing them must also present themselves as such.

On the part of the regulatory and supervisory authorities, they need to carry out more aggressive and timely on-site and off-site supervision of MFBs' activities. As contained in the policy framework of MFBs in Nigeria, regulators should ensure that MFBs are not just physically present in a community but economically present too. Regulators should scrutinize the books of MFBs to ascertain the number of local customers, gender balance, types and structure of assets (earning and non-earning) maintained by MFBs per period. With proper enforcement of policy guidelines and rules guiding MFBs, regulators can help check over-trading and under-trading.

\section{Conflicts of Interest}

The authors declare no conflicts of interest regarding the publication of this paper.

\section{References}

Acerbi, C., \& Tasche, D. (2002). On the Coherence of Expected Shortfall. Journal of Banking and Finance, 26, 1487-1503. https://doi.org/10.1016/S0378-4266(02)00283-2

Artzner, P., Delbaen F., Eber, J., \& Heath, D. (1999). A Characterization of Measures of Risk, Technical Report 1186. Ithaca, NY: Cornell University.

Bajram, N., \& Can, M. (2013). Asset and Liability Management Models in Decision Making. Journal of Business and Finance, 1, 11-16.

Boender, G. C. E. (1997). A Hybrid Simulation/Optimization Scenario Model for Asset/Liability Management. European Journal of Operational Research, 99, 126-135. https://doi.org/10.1016/S0377-2217(96)00387-6

Campion, A. (2000). Improving Internal Control: Technical Guide \#1. Washington DC: GTZ and MicroFinance Network, 55-60.

Campion, A., \& Frankiewicz. C. (1999). Guidelines for the Effective Governance of Microfinance Institutions, Occasional Paper \#3. Washington DC: MicroFinance Network, 67-72.

Cariño, D. R., Kent, T., Myers, D. H., Stacy, C., Sylvanus, M., Turner, A.L., Ziemba, W.T. et al. (1994). The Russell-Yasuda Kasai Model: An Asset/Liability Model for a Japanese Insurance Company Using Multistage Stochastic Programming. Interfaces, Edelman Prize Issue, 24, 29-49.

Cariño, D., \& Ziemba, W. T. (1998). Formulation of the Russell-Yasuda Kasai Financial Planning Model. Operations Research, 46, 433-444.

https://doi.org/10.1287/opre.46.4.433

CBN (2011). Microfinance Certification Programme: Study Manual (Revised). Lagos: CBN Press Limited.

Cumova, D., \& Nawrocki, D. (2003). Portfolio Optimization in an Upside Potential and Downside Risk Framework. http://google.com

Defourny, B., Ernst, D., \& Wehenkel, L. (2008). Multistage Stochastic Programming: A Scenario Tree Based Approach to Planning under Uncertainty.

Drijver, S. (2005). Asset Liability Management for Pension Funds Using Multi-Stage Mixed Integer Stochastic Programming. The Netherlands: Labyrint Publication.

Drijver, S., Haneveld, K., \& van de Vlerk, W. (2000). Asset and Liability Management 
Modelling Using Multi-Stage Mixed-Integer Stochastic Programming. http://www.rug.nl/research/portal

Dunford, C. (2000). The Holy Grail of Microfinance: Helping the Poor and Sustainable? Small Enterprise Development, 11, 40-44. https://doi.org/10.3362/0957-1329.2000.008

Ellerman, D. (2007). Microfinance: Some Conceptual and Methodological Problems. In T. Dichter, \& M. Harper (Eds.), What's Wrong with Microfinance? England: Practical Action Publishing.

Fernado, N. A. (2007). Managing Microfinance Risks: Some Observations and Suggestions. Asian Journal of Agriculture and Development, 4, 1-22.

Gondzio, J., \& Kouwenberg, R. (2001). High Performance Computing for Asset Liability Management. Operations Research, 49, 879-891.

Grebeck, M., \& Rachev, S. (2005). Stochastic Programming Methods in Asset-Liability Management. Investment Management and Financial Innovations, 1, 82-90.

Greuning, V., Gallardo, J., \& Randhawa, B. (1998). A Framework for Regulating Microfinance Institutions (pp. 7, 32-33). Washington DC: World Bank.

Hoevenaars, R. P., Molenaar, R. D., Schotman, P. C., \& Steenkamp, T. B. (2008). Strategic Asset Allocation with Liabilities: Beyond Stocks and Bonds. Journal of Economic Dynamics \& Control, 32, 2939-2970. https://doi.org/10.1016/j.jedc.2007.11.003

Hoyland, K., \& Wallace, S. W. (2001). Generating Scenario Trees for Multistage Decision Problems. Management Science, 47, 295-307.

Joachim, B. (2000). Liquidity Management: A Toolkit for Microfinance Institutions. Bonn and Eschborn: Deutsche Gesellschaft für Technische Zusammenarbeit (GTZ). http://www.gtz.de

Koskosides, Y., \& Duarte, A. (1997). A Scenario-Based Approach for Active Asset Allocation. Journal of Portfolio Management Winter, 23, 74-85. https://doi.org/10.3905/jpm.23.2.74

Kouwenberg, R., \& Zenois, S. A. (2001). Stochastic Programming Models for Asset and Liability Management.

Krokhmal, P., Uryasev, S., \& Zrazhevsky, G. (2002). Risk Management for Hedge Fund Portfolios: A Comparative Analysis of Linear Portfolio Rebalancing Strategies. Journal of Alternative Investments, 5, 10-29. https://doi.org/10.3905/jai.2002.319040

Kusy, M. I., \& Ziemba, W. T. (1986). A Bank Asset and Liability Management Model. Operations Research, 34, 356-376. https://doi.org/10.1287/opre.34.3.356

Ledgerwood, J. (1999). Microfinance Handbook: An Institutional and Financial Perspective for Sustainable Banking with the Poor. Washington DC: World Bank. http://www.worldbank.org

Lintner, J. (1965). The Valuation of Risk Assets and the Selection of Risky Investments in Stock Portfolios and Capital Budgets. Review of Economics and Statistics, 47, 443-450.

Mack, B. J. (2015). Practical Applications of on the Holy Grail of "Upside Participation and Downside Protection". The Journal of Portfolio Management, 3.

Mago, S., Hofisi, C., \& Mago, S. (2013). Microfinance Institutions and Operational Risk Management in Zimbabwe: Insights from Masivingo Urban. Mediterranean Journal of Social Sciences, 4, 159-168.

Mangold, R. (2016). Do Microfinance Investment Managers Add Value, and How? Enterprise Development and Microfinance, 27.

Markowitz, H. M. (1952). Portfolio Selection. Journal of Finance, 7, 77-91.

Markowitz, H. M. (1959). Portfolio Selection, Efficient Diversification of Investments. 
Hoboken, NJ: John Wiley\& Sons.

Merton, A. (1973a). Macroeconomic Factors Do Influence Aggregate Stock Returns. The Review of Financial Studies, 15, 751-782.

Ndibe, L., Igbokwe, A., Dauda, A., \& Abdulazeez, D. (2013). The Trend Analysis of Asset and Liability of Microfinance Banks. European Journal of Business and Management, 5, 10-18.

Rockafellar, R. T., \& Uryasev, S. (2000). Optimization of Conditional Value at Risk. Journal of Risk, 2, 21-41.

Ross, S. A. (1976). The Arbitrage Pricing Theory of Capital Asset Pricing. Journal of Economic Theory, 13, 341-360. https://doi.org/10.1016/0022-0531(76)90046-6

SEDIN (2015). Loan Pricing of Nigerian Microfinance Banks: Survey \& Methods of Assessment, GIZ's Pro-Poor Growth and Promotion of Employment Programme, August. Abuja: GIZ German Co-Operation.

Sharpe, W. F. (1964). Capital Asset Prices: A Theory of Market Equilibrium under Conditions of Risk. Journal of Finance, 19, 234-246.

Sortino, F., Van Der Meer, R., \& Plantinga, A. (1999). The Dutch Triangle. Journal of Portfolio Management, 26, 50-58. https://doi.org/10.3905/jpm.1999.319775

Tokat, Y., Rachev, S. T., \& Schwartz, E. S. (2003). Asset and Liability Management: A Review and Some New Results in the Presence of Heavy Tails. In S. T. Rachev (Ed.), Handbook of Heavy Tailed Distributions in Finance (pp. 509-546). Amsterdam: Elsevier Science.

Yang, X. (2009). Applying Stochastic Programming Models in Financial Risk Management. PhD Dissertation, Edinburgh: University of Edinburgh.

Yang, X., Gondzio, J., \& Grothey, A. (2009). Asset-Liability Management Modeling with Risk Control by Stochastic Dominance (pp. 104-116). Technical Report ERGO-09-002, Edinburgh: University of Edinburgh.

Zenios, S. A. (1995). Asset/Liability Management under Uncertainty for Fixed-Income Securities. Annals of Operations Research, 59, 77-97.

https://doi.org/10.1007/BF02031744

Zenios, S. A. (1999). High-Performance Computing for Financial Planning: The Last Ten Years and the Next. Parallel Computing, 25, 2149-2175.

https://doi.org/10.1016/S0167-8191(99)00083-6 